\title{
¿Tienen historia los objetos? \\ El encuentro de Pasteur y de Whitehead en un baño de ácido láctico*
}

\author{
BRUNO LATOUR \\ Centre de Sociologie de l'Innovation, École des Mines, París
}

Pero en el mutndo real es más importante que una proposición sea interesante a que sea verdadera. Lo importante de la verdad es que se sume al interés [p. 259].

Hay que rccordar que la expresión 'mundo actual' se parece a 'ayer' y 'mañana' en que cambia su significado en función del punto en que se' está [p. 65].

A.N. WhrtehEad, Process and Reality

Pretendo investigar de qué manera la metafísica de Whitehead puede arrojar alguna luz sobre un problema difícil de la historia social de las ciencias, la historicidad de las cosas, que hasta ahora no ha tenido solución satisfactoria. Como buen filósofo empírico, partiré de un ejemplo, el del descubrimiento-invención-construcción por Pasteur del fermento del ácido láctico en 1857.

En este artículo examinaré dos cosas: ¿cómo podemos replantearnos una gran cuestión de filosofía de la historia a partir de Whitehead? ¿Cómo se comporta su filosofía cuando hay que afiontar los detalles concretos de una situación experimental?

\section{Algunos debates recientes en el estudio de las ciencias}

Antes de sumergir a Whitehead en un baño de ácido láctico, conviene resumir los episodios precedentes para el lector.

La simple noción de una sustancia duradera que mantiene cualidades persistentes, tanto esencial como accidentalmente, expresa una abstracción que resulta útil para muchos astuntos de la vida. Pero en cuanto intentamos usarla como una afirmación fundamental sobre la naturaleza de las cosas, por sí misma muestra que es errónea. Surge a partir de un error y nunca ha tenido éxito en ninguna de sus aplicaciones. ${ }^{1}$

* Artículo publicado en francess en el libro editado por Isabelle Stengers, L'effet Whitehead, Paris, Vrin, 1994, pp. 197-217. Traducido por Javier Echeverria. 
Esta crítica al substancialismo, tan importante para Whitehead, podría ser compartida por numerosos historiadores de las ciencias, pero por razones muy diferentes. Según estos últimos, cuando se relata un descubrimiento no se debe recurrir a ninguna substancia exterior al trabajo humano para explicar su génesis. ${ }^{2}$ Ciertamente, al igual que Kant, la mayor parte de los nuevos historiadores no niegan su existencia, con el fin de evitar caer en el idealismo, pero en cuanto a los atributos concretos, sólo los hacen emerger a partir del espíritu que conoce, o más recientemente a partir de la práctica del grupo de sabios que manipula y experimenta en el recinto cerrado y local del laboratorio. ${ }^{3}$ Para criticar el substancialismo, simplemente hay que abstenerse de atribuir un papel en la historia de un descubrimiento a los seres no humanos por sí mismos, y hay que construir el relato con la sola ayuda de las prácticas, los lugares, los instrumentos, las autoridades, las instituciones y los acontecimientos históricos que nos proporciona el contexto. Se confía así en que una multiplicidad de pequeñas determinaciones que se suman las unas a las otras llegará a contar tanto como la substancia que siempre estaba presupuesta en los relatos "a la antigua» de los descubrimientos. Como bien ha mostrado Isabelle Stengers en un libro reciente, ${ }^{4}$ para el científico practicante hay algo de inverosímil en este enfoque, algo irreal, y ello no sólo en el sentido filosófico del término, sino también en el sentido más común de improbable. Falta algo esencial. ¿Falta precisamente la esencia? No. El interés de Whitehead estriba precisamente en imaginar un realismo sin sustancia, un realismo histórico radical. «El castillo roquero de Edimburgo existe momento tras momento, y siglo tras siglo, en virtud de la decisión efectuada por su propia trayectoria histórica de ocasiones antecedentes. $\aleph^{5}$

Para escapar de la historia social de las ciencias, del constructivismo social y de los diferentes avatares del kantismo, ha hecho falta pasar de un principio restringido de simetría a un principio de simetría generalizado. El primer principio exigía a los historiadores que juzgaran equilibradamente los relatos de descubrimiento, midiendo con el mismo rasero a los sabios que se habian equivocado y a los sabios que habían tenido razón. ${ }^{6}$ Dicho principio, diametralmente opuesto a la tradición epistemológica francesa, la cual exigía, por el contrario, que se distinguiera entre la "ciencia caduca" y la "ciencia ratificadan, ${ }^{7}$ ha dado lugar a hermosos efectos de escenificación historica. Las victorias de Boyle sobre Hobbes, de Newton sobre el cartesianismo o de Pasteur sobre Pouchet, ya no difieren de las victorias provisionales de Napoleón sobre el emperador Alejandro o de Pompidou sobre Poher. La historia de las ciencias deja de ser distinta de la historia a secas, "plena de ruido y furor».

Sin embargo, el precio a pagar por esta reunificación entre la historia y la historia de las ciencias resulta muy alto. El principio restringido de símetría no consigue igualar las oportunidades de los vencedores y de los vencidos (racionales e irracionales, de aquí en adelante) más que a base de prohibir a los protagonistas el acceso a los fenómenos mismos, a pesar de 
que los consideran como su única razón de ser. Por decirlo al modo de Whitehead, a propósito de Hume, hay algo heroico en esa abstención. Mientras las cosas mismas proliferan en las manos y en los cuerpos de todo el mundo, el historiador simétrico habría de ser el único que se abstiene de tocarlas, con el fin de poder clasificar a los vencedores y a los vencidos. La naturaleza no interviene en las interpretaciones que hacemos al respecto - afirman todos ellos, con la ascesis de un yogi. ${ }^{\mathrm{g}}$

Se comprende la razón de un designio así. Los historiadores que son partidarios de la simetría reaccionan contra los abusos de los substancialistas, los cuales se contentan con juzgar a los vencedores de la historia de las ciencias explicando hipócritamente que han ganado porque eran más racionales o porque tenían un acceso mayor a la naturaleza de las cosas. Al insistir, por vez primera, en las dificultades de la experiencia, en las imprecisiones de los instrumentos, en la irremediable localización de las prácticas, en la ambigüedad de las interpretaciones y en la importancia de la comunidad de colegas, más o menos dignos de crédito, los historiadores constructivistas tienen, en efecto, mucho que aportar, como lo había hecho antes que ellos en relación con la percepción su precursor, Hume, ridiculizando a quienes creen beneficiarse de un acceso inmediato a lo real y a quienes consideran ciertos hábitos sociales y cognitivos, surgidos anteayer, como la esencia permanente de las cosas.

El principio generalizado de simetría consigue evitar que esta ascesis heroica conduzca a la anorexia. ${ }^{9}$ Esta vez ya no se trata de igualar las oportunidades de los vencedores y de los vencidos prohibiendo por igual a ambos grupos el acceso a lo real, sino más bien de dejar a todos los grupos que construyan simultánea y simétricamente su realidad natural y su realidad social. ;Como si fueran yogis que han estado privados largo tiempo de alimentos y se han visto obligados a dormir demasiadas noches sobre lechos de púas, se permite por fin a los descubridores que se empachen de realidad y duerman sobre colchones de pluma! Este ligero vaivén basta para liberarse del kantismo, puesto que, para explicar un descubrimiento, ya no se está obligado a elegir entre un acceso privilegiado a lo real o una determinación en base a miles de pequeñas causas sociales y prácticas. Uno se da cuenta, en efecto, de que la definición de lo real como amarre contra el idealismo sólo tenía sentido por oposición al espíritu cognoscente (o al laboratorio, o al paradigma). A revolución copernicana, contrarrevolución copernicana y media. El descubridor establece a la vez lo que es, el mundo en el que se sitúa, y las numerosas formas de causalidad social, práctica e histórica que son compatibles con el tipo de fenómenos con los que puebla lo colectivo. La diferencia entre las cuestiones ontológicas, epistemológicas y sociológicas se difumina. La cuestión pasa a ser más bien la siguiente: ¿en qué mundo socionatural aceptamos vivir? El principio generalizado de simetría no abole el principio restringido de simetría, sino que lo amplía, y ello tanto a la 
cuestión de la naturaleza como a la de la sociedad, permitiendo la aparición de un objeto nuevo: el colectivo de humanos y no humanos. ${ }^{10}$

Sin embargo, esta propuesta carece de una metafísica a la altura de sus ambiciones. Aunque ya no sea antropomórfica, resulta tan frágil como pueda serlo el sentido que se atribuya a la palabra 'colectivo'. Si mediante esa palabra se designa la actividad demiúrgica de investigadores capaces de engendrar, no sólo la naturaleza, sino también la sociedad y la historia en la que se sitúan, nos aproximamos peligrosamente a los grandes relatos del idealismo absoluto, que creían, también ellos, sobrepasar a Kant. Si se trata de una proliferación semiótica que dota de ciertas propiedades a los humanos, a los no humanos, a los objetos que circulan, a las posiciones enunciativas y al contexto que se inscribe en el texto, entonces nos sumergimos en el discurso, en campos de posiciones sin sujetos, y con ello nos alejamos del realismo más de lo que pretendíamos. La «muerte del hombre" da brutalmente paso al "superhombre". Si, por último, se trata de dejar que los no humanos se multipliquen, tanto en la sociedad como en los sujetos, se corre el riesgo de naturalizar el conjunto de la historia y sus relatos, sin poder dotar ya a los objetos de su propia incertidumbre, de su trascendencia, de su «temblor». Pasamos así a una voluntad de poder que anclaría brutalmente el discurso y las acciones en la biología y en la física.

Para estar seguros de escapar a estos tres peligros - reducción a la sociedad, reducción al lenguaje, reducción a la naturaleza- hay que rechazar la ambiguiedad de la palabra 'colectivo' e incluso hay que abandonar todo "colecto-centrismo", así como las nociones de actor, acción, sujetos, objetos, humanos y no humanos que nos sirvieron provisionalmente para escapar del kantismo. Como Whitehead, hay que atreverse a comerciar con la metafísica a pesar del embargo promulgado contra ella tanto por la filosofía analítica como por el constructivismo, sca éste social o simétrico.

Llegados a este punto y tras haber resumido los episodios precedentes, conviene no obstante cambiar de procedimiento y seguir un caso concreto para no perder el hilo de ese realismo histórico sin substancia intemporal que nos permite imaginar Whitehead.

\section{Relato de un descubrimiento de Pasteur}

En 1858, poco tiempo después de haber "puesto en evidencia» el fermento de la levadura de cerveza, Pasteur relata, en una memoria a la Academia de Ciencias, el descubrimiento de un fermento propio del ácido láctico."

Para hacer la historia de este descubrimiento, nos basta con una forma muy elemental de escenificación histórica. Hoy en día, la fermentación láctica no es objeto de discusión alguna y resulta posible encargar sobre catálogo las variedades y las cantidades de fermento para las lecherías, mantequerías y queserías de todo el planeta. Pero basta con uremitirse a las condiciones de 
la época" para evaluar la originalidad de esa memoria, y por consiguiente la parte que Pasteur puede reivindicar de su propia tarea. Hacia la mitad del siglo $\mathrm{Xx}$, en el entomo de los sabios influidos por la química de Liebig, la presencia de un microorganismo específico para explicar las fermentaciones suponía un paso atrás, puesto que la química acababa de conseguir su derecho de ciudadanía y su status científico desembarazándose de las oscuras explicaciones vitalistas. ${ }^{12}$ Siguiendo este tipo de química, la fermentación podía explicarse de manera puramente química mediante la degradación de las materias inertes, sin intervención de nada viviente. De todos modos, los especialistas de la fermentación láctica no habían visto nunca microorganismos duraderamente asociados a la transformación del azúcar.

Investigaciones minuciosas no han podido hasta ahora llegar a descubrir el desarrollo de seres orgánicos. Los observadores que han llegado a reconocerlos han establecido al mismo tiempo que eran accidentales y dañaban el fenómeno. Por consiguiente, los hechos parecen ser muy favorables a las ideas del Sr. Liebig o a las de Bezelius. Según el modo de ver del primero, el fermento es una substancia excesivamente alterable que se descompone y que provoca la fermentacion como consecuencia de la alteración que ella misma experimenta, cuarteando por contacto y desagregando el grupo molecular de la materia fermentable. Según el Sr. Liebig, ésta es la causa primera de todas las fermentaciones y el origen de la mayor parte de las enfermedades contagiosas. Para Berzelius, el acto químico de la fermentación tiene lugar mediante las acciones de contacto. Estas opiniones obtienen cada dí mayor crédito [...] Dichos trabajos concuerdan al rechazar ta idea de cualquier tipo de influencia de lo orgánico y de la vida sobre la causa de los fenómenos que nos ocupan [subrayados míos].

$Y$ Pasteur añade: «me veo conducido a una manera de ver enteramente diferente». El descubridor parece tanto más activo cuanto que tiene a todo el mundo en su contra: la opinión unánime de los químicos y las investigaciones minuciosas de los especialistas. El descubridor no levanta el velo tras el cual se escondía desde siempre el fermento de la fernentación láctica. Actúa. Tratándose de un acontecimiento histórico que invierte una situación que le era desfavorable, puede ser contado como lo haría un historiador que siguiera al oscuro general De Gaulle desde junio de 1940 en Londres hasta su triunfo, cinco años más tarde, en los Campos Elíseos. En cualquier caso, la acción de Pasteur no consiste en imponer un cuadro o una visión para la fermentación, cosa que no podría hacer - aunque más tarde se planteará el problema en estos términos, como veremos. Afirma así que «se ve conductdo a una manera de ver». Su actividad propia consiste en dejarse llevar por la "propensión de las cosas", por retomar la bella expresión de François Julien. ${ }^{13}$ Incluso cuando actúa para hacer emerger el fermento en contra de la opinión general, todavía sigue dejándose llevar por las cosas, vinculando de otra manera la suerte de un sujeto 
-autor creíble que reivindica la polémica y la acción-y la de un objeto -que conduce al sujeto a modificar su visión.

En el caso de la historia política y militar, existen recursos que permiten sopesar el papel respectivo de la ocasión, las circunstancias, el talento propio, la suerte y, por último, la atribución de responsabilidades a determinados operadores que son reconocidos como jefes o como demiurgos. Cuando se trata de hacer intervenir en el relato seres que uno ha descubierto, el historiador de las ciencias se vuelve más reticente, más dubitativo. Por muy heterogéneos que sean los factores a los que recurre la historia, nunca lo son tanto como en la historia de las ciencias, en la cual hay que integrar la corta existencia de Pasteur, la mayor duración de la química o del segundo Imperio, la duración todavía más larga de las fermentaciones alcohólicas y lácticas, que se remontan al Neolítico, y la duración infinitamente más larga, absolutamente más larga, del fermento de ácido láctico, que ya está presente desde siempre. Dicho de otra manera: el historiador de las ciencias se ocupa de un monstruo mayor que el historiador a secas. Una vez que fue descubierto por Pasteur en 1857, el fermento de ácido láctico ya ha estado ahí desde siempre, incluidas las calabazas del Homo sapiens en el Neolítico, y así sigue siendo responsable hoy en día del suero que se agría en todas las lecherías del planeta. ¿Cómo se podría hacer la historia de la creación de un ser que de inmediato parece desbordar su marco histórico para remontarse a la totalidad del tiempo y expandirse en la totalidad del espacio?

La única solución, común en el caso de la historia, consiste en atribuir carácter histórico a todos los elementos que intervienen en el relato. ${ }^{14} \mathrm{De}$ Gaulle se transforma, pero también se transforman Churchill, Alemania, los radares, las opiniones públicas, los submarinos, el cálculo de los convoyes perdidos, la deuda respectiva de los bancos centrales, y así sucesivamente, según escalas y ritmos diferentes. De manera más o menos similar, siempre hay reciprocidad en la aventura, en el acontecimiento. De Gaulle modifica a Churchill, quien a su vez le transforma. Precisamente esta reciprocidad parece imposible en la historia de las ciencias: jhabría que hacer compartir el acontecimiento entre Pasteur y el ácido láctico! Y sin embargo, la simetría generalizada exige que se comparta. No sólo el fermento "llega" a Pasteur -convirtiendo a este honorable químico provinciano en un maestro de la microbiología mundial-, sino que Pasteur «llega» al fermento del ácido láctico -convirtiendo esta fermentación por contacto en el cultivo de un fermento para el cual el azúcar es un alimento. Hay que admitirlo, sí: Louis Pasteur, el joven de Lille, cuenta como un episodio en el destino, en la esencia, en la trayectoria del fermento láctico. Se comprende lo absurdo de una posición así y el escándalo que ha podido suscitar, ${ }^{15}$ sobre todo si, en vez de aplicarse al fermento, todavía bastante próximo a los organismos inmersos en la agitada historia de los seres vivos, el 
argumento se aplicara a la gravedad o a la cosmología. ¿Le llegaria Newton a la gravitación universal? ¿Le llegaria el CERN al Big Bang?

Si sólo se hablara de representaciones, buscando de nuevo refugio en el mullido colchón kantiano, el asunto, por supuesto, no ofrecería dificultad alguna. Pasteur transformó las ideas que los químicos y los mantequeros tenían "sobre» la fermentación láctica, como Newton modificó nuestras ideas sobre la acción a distancia de los cuerpos celestes. Podríamos volver a la historia con mucha mayor facilidad, porque todo quedaria "entre hombres», con sus representaciones, sus visiones del mundo y sus intereses, más o menos apasionados. La historia de las ciencias, fuera social o intelectual, podría desplegarse con tanta mayor audacia cuanto que se limitaria a las puras representaciones, dejando fuera del alcance a los fenómenos mismos. Pero con la simetría generalizada queremos alcanzar los fenómenos, salir del jardín de infancia del idealismo y reencontrarnos con el realismo, con los riesgos de la ontología, sin perder por ello las incertidumbres de la historia ni la localización de las prácticas. ${ }^{16}$ Por estrafalaria que parezca, hay que explorar esta vía y hablar de Pasteur como de un acontecimiento que le llega al ácido láctico. Lo que parecía absurdo en una metafísica de la esencia y de los atributos puede convertirse en un juego de niños para una ontología de los acontecimientos y de las relaciones. ${ }^{17}$

\section{Algunas ontologias de geonetria variable}

Utilizando la terminología de Whitehead, el laboratorio de Pasteur se nos aparece como una ocasión ofrecida a las trayectorias de entidades que heredan circunstancias precedentes al "decidir» perseverar en el ser de una manera nueva.

Algunas entidades van a recorrer el laboratorio como prácticas estabilizadas. Este es el caso del propio ácido láctico:

El ácido láctico ha sido descubierto por Scheele, en 1780 , en el suero agriado. Su procedimiento para extraerlo de dicha materia seguiria siendo hoy en día el mejor a seguir. Primero hizo que el suero se redujera a la octava parte mediante evaporación. Lo filtró, lo saturó mediante cal para precipitar el fosfato de cal. El licor fuc fittrado y diluido en tres veces su peso de agua: vertió en él ácido oxálico gota a gota para precipitar toda la cal. Evaporó el licor hasta que tuvo consistencia de miel [...].

El ácido no se presenta como una sustancia duradera en el tiempo, definida por sus atributos, sino mediante un conjunto de verbos que remiten a gestos en los laboratorios. Se refiere a un procedimiento y no tiene otra definición más que la de ser coextensivo al conjunto de dichas maniobras. Poco importa que la lista de las operaciones sea larga, puesto que cada una de ellas forma parte de la rutina de un laboratorio de química 
bien equipado. El encaje de los subprogramas de acción no hace más frágil su esencia, puesto que los químicos expertos comprenden sin esfuerzo el significado de los gestos para filtrar, evaporar, precipitar, y consideran su mutua disposición como una sola y única caja negra.

No ocurre lo mismo con el fermento, del que duda toda la comunidad científica en 1857.

Si se examina con atención una fermentación láctica ordinaria, hay casos en los que, por encima del depósito de la creta y de la materia azoada, pueden reconocerse manchas de una substancia gris que llega a veces a formar una zona en la superficie del sedimento. Esta materia ha sido llevada alli por el movimiento de los gases. Su examen al microscopio apenas permite, cuando no se está prevenido, distinguirla de la caseína, del gluter disgregado, etc.: de tal modo que nada indica que sea una materia especial, ni que haya surgido durante la fermentación. Su peso aparente siempre es muy pequeño si se compara con el de la materia azoada, necesaria desde el principio para la realización del fenómeno. Por último, a menudo está mezclada hasta tal punto con la masa de caseína y de creta que no ha lugar creer en su existencia. Sin embargo, ella desempeña el papel principal.

Al revés que el ácido láctico, la existencia misma del fermento está en cuestión. Apenas hay gestos rutinarios que permitan garantizar su presencia regular. La entidad misma sólo se define por "rasgos mínimos" que aparecen como "manchas de una substancia gris que llega a veces a formar una zona en la superficie de un sedimento". iApenas si se puede existir menos! El contraste resulta mucho más fuerte si se compara con la frase desafiante que aparece al final del párrafo. Pasteur se ha kvisto conducido a una manera de ver enteramente diferenten. Este cambio y este giro dependen de esta nueva conversión mediante la cual un ser del que «no ha lugar creer en su existencia», "idesempeña sin embargo el papel principal!».

Para seguir el hilo de cómo el fermento, criticado por todos, invisible, pobre, mancha al fondo de un vaso de cristal, va a convertirse pronto en el "único responsable» de la fermentación láctica, las expresiones de 'sujeto' y de 'objeto' pasan a tener poca utilidad, como puede comprenderse. Pasteur apuesta fuerte en este asunto, tanto como el fermento, Liebig y los mantequeros. No vemos a un hombre dotado de facultades en el momento de descubrir un ser definido por sus atributos. Vemos un cuerpo de miembros múltiples y parciales en trance de hacer llegar a su laboratorio, mediante una serie de experimentos, una sucesión regular de acciones:

En primer lugar indicare la manera de aislar [esta materia especial] y de prepararla en su cstado puro. De la levadura de cerveza extraje su parte soluble, manteniéndola durante un lapso de tiempo a la temperatura del agua hirviendo en quince a veinte veces su peso en agua. El licor, solución compleja de materia albuminoide y mineral, se filtra con cuidado. Se disuelve en él alrededor de 50 a 100 gramos de azúcar por litro, se añade creta y se sientbra un rastro de esta materia gris de la que 
acabo de hablar, extratda de una buena fermentación láctica ordinaria. Después se lleva la estufa hasta 30 o 35 grados. También es bueno hacer pasar una corriente de ácido carbónico para expulsar el aire del frasco, al cual se le adapta un tubo curvado que se sumerge en agua. A la mañana siguiente, se manifiesta una fermentación viva y regular.

En el laboratorio, el cuerpo cuidadoso y hábil de Pasteur sirve de ocasión, de circunstancia, de concreción para el establecimiento duradero de una fermentación láctica. Por medio de los gestos (filtrar, disolver, añadir), de los ingredientes (levadura de cerveza, licor, creta), de los montajes (grifos, recipientes, estufas, tubos), de los instrumentos de medida (termómetros, balanzas, termostatos) y de los pequeños trucos del oficio (es bueno), la fermentación resulta visible y estable. En este estadio de variación, la esencia de la fermentación no es nada más que ese mismo despliegue en esas circunstancias, prácticas y locales.

En este caso, hacer la historia va mucho más allá que la simple «vuelta a las incertidumbres de la época». Ya no se trata sólo de reencontramos con Pasteur temblando en su laboratorio ante la idea de perder su fermentación, así como el incierto fermento que le parece ser "correlativo a la vida». La propia fermentación láctica tiembla también. Esta manifestación «viva y regular», controlada, no le había sucedido nunca, desde que el mundo es mundo. El pequeño laboratorio del decano de la Facultad de Ciencias de Lille constituye una bifurcación decisiva en la trayectoria de esta fermentación, puesto que justamente allí es donde se hace pura y visible. No sólo Pasteur modifica su "representación» de la fermentación; también ésta misma, en su propio ser, en su historia, en sus ascendencias y descendencias, modifica sus manifestaciones. Si Pasteur duda, la fermentación también duda.

La ambivalencia, la ambigüedad, la plasticidad, no sólo llegan a molestar a los humanos que avanzan a tientas hacia fenómenos en sí mismos seguros; ${ }^{18}$ también acompañan a los seres a los que el laboratorio les ofrece una nueva posibilidad de existencia, una oportunidad histórica. Sin Pasteur, sin la filtración, sin el tubo curvado, sin el acto de siembra en un medio de cultivo, la fermentación nunca hubiera sido amanifiesta». Había conocido otras existencias antes de 1857, en otros lugares, pero su nueva concreción en la novísima Facultad de Ciencias de Lille, en manos de un químico nuevo y ambicioso, le ofrece una nueva existencia única, fechada, localizada, compuesta en parte por Pasteur - él mismo transformado por su segundo gran descubrimiento- y en parte por el laboratorio -él mismo cuerpo y alma de Pasteur, inteligencia distribuida, teoría materializada en los instrumentos, asamblea muda y materializada de toda la química de la última centuria. Hacemos así la historia de Pasteur y de su fermento, del fermento y de su Pasteur; hablamos así de acontecimientos definidos únicamente por sus relaciones. 


\section{Del acontecimiento a su substancia}

Al calificar de esta manera la historia corriente de un investigador, de una disciplina, de un montaje, de un fermento y de una teoría, no perdemos de vista la substancia y sus atributos; pero el sentido de la palabra 'substancia' va a cambiar profundamente, convirtiéndose en la progresiva atribución por una institución de propiedades estables vinculadas a un nombre ligado de forma duradera a una práctica, y todo ello circulando en un circuito relativamente estandarizado. ${ }^{19}$ Esta transición desde el acontecimiento a la substancia definida plantea de nuevo un temible problema de descripción y de interpretación, del que Pasteur se libera mediante dos contradicciones aparentes.

Al empezar su Memoria, el autor todavía no sabe qué propiedades atribuir a qué esencias. Al final, el fermento es tan consistente como la cerveza, a su vez redescubierta. La substancia dotada de atributos ofrece un caso particular del acontecimiento definido por sus relaciones, una cierta manera de resumir, de hacer rutinarios, de estabilizar y de institucionalizar los acontecimientos. Todo ocurre como si se empezara por los atributos con el fin de llegar a una esencia. Este pasaje, pocas veces estudiado, puede verse entre dos párrafos de la Memoria:

Ahora vemos cuáles son los caracteres de esta substancia, cuya producción es correlativa a los fenómenos comprendidos bajo la denominación de fermentación láctica. Considerada como masa, se parece por completo a la levadura ordinaria escurrida o prensada. Es un poco viscosa, de color gris. Al microscopio, está forma$d a$ por pequeños glbbulos o nudillos muy cortos, aislados o en amasijo, que llegan a constituir mechas irregulares que se parecen a las de algunos precipitados amorfos [...] Puede ser recogida y transportada lejos sin perder su energía. Su actividad se debilita cuando se la seca o se la hace hervir en agua. En fin, basta muy poco de esta levadura para transformar un peso considerable de azúcar.

Encontramos así todos los caracteres generales de la levadura de cerveza; probablemente ambas sustancias poseen organizaciones que, en una clasificación natural, deben ocupar dos géneros vecinos o dos familias próximas.

En el primer párrafo, la esencia sólo se define mediante pruebas a las que se somete a un $x$, a una "materia especial" anónima, cuyas respuestas, que han pasado a ser estables recientemente gracias a los cuidados y a la habilidad del sabio, así como al genio del lugar, quedan registradas. Cada prueba sorprende todavía hoy por su lozanía: ix puede ser transportada sin perder fuerza! ¡Basta muy poco para modificar un peso considerable de azúcar! Los atributos flotan todavía, sin poder vincularse a un substrato. En el texto se advierten aún las dudas, los escrúpulos, las moratorias de Pasteur ante esta materia viscosa y gris que resiste a la desecación o a la ebullición. Cada prueba la define aún en toda su lozanía, como si sólo pudieran inducirse competencias a partir de resultados turbadores. 
Pero a partir del párrafo siguiente la consolidación se ha producido. "La materia especial» no sólo se parece ahora a la levadura de cerveza, sino que ya no se compone únicamente de glóbulos y de mechas irregulares. El fermento, ahora con nombre, se convierte en una substancia y ocupa una posición perfectamente localizable en una clasificación de géneros y de especies. Los atributos, que flotaban a su antojo, pasan a ser las marcas de una esencia duradera - y no sólo de una rutina estabilizada, como el ácido láctico anteriormente estudiado.

¿Cómo explicar el paso de una larga serie de pruebas inciertas a un ser resumido mediante un nombre? ¿Por qué los atributos acaban por alojarse en una substancia como un vuelo de palomas de vuelta al palomar?

La respuesta de los historiadores de las ciencias que se inspiran en el primer principio de simetría no tiene duda. Ha hecho falta que el propio Pasteur diera un pequeño empujón para reunir en un concepto el polvo indeterminado de los hechos. Sin el presupuesto del microorganismo, numca hubiera podido resumir en un solo fermento la larga lista de pruebas, ni tampoco los resultados hubieran permitido suponer una competencia así, de microbio orgánico. Desde Duhem, en efecto, según los historiadores de las ciencias siempre se precisa una teoría, un prejuicio, un presupuesto, un marco conceptual, un paradigma, con el fin de poner orden en los datos, con los cuales uno nunca se puede confrontar cara a cara. Retorno obligado a Kant y a sus epígonos sociólogos. Curiosamente, Pasteur se plantea la misma cuestión y parece abrazar la tesis de los constructivistas antes de contradecirse por segunda vez:

A lo largo de toda esta Memoria, he razonado conforme a la hipótesis de que esta levadura es orgánica, que es un ser vivo y que su acción química sobre el azúcar es correlativa a su desarrollo y a su organización. Si se me llegara a decir que en estas conclusiones voy más alla de los hechos, respondería que eso es cierto, en el sentido de que me coloco francamente en un orden de ideas que, hablando rigurosamente, no pueden ser demostradas de manera irrefutable. Esa es mi manera de ver. Cuantas veces se ocupe un químico de esos misteriosos fenómenos, y si tiene la suerte de hacerles dar un paso importante, se verá llevado instintivamente a situar su causa primera en un orden de reacciones que tiene relación con los resultados generales de sus propias investigaciones. Así es el proceder lógico del espíritu humano en todas las cuestiones controvertidas.

En la más pura tradición racionalista, Pasteur insiste en que se precisa una teoría para hacer hablar a los hechos, y moviliza simultáneamente el instinto, la lógica del espíritu humano y las maneras de ver. Como Rouletabille, sabe que hay que seguir primero "la buena guía de la razón». Pero no se limita a esta solución del "pequeño empujón", que sin embargo encantaría a los constructivistas sociales. Sin temor a contradecirse, se pasa luego al realismo más tradicional y afirma tranquilamente: 
Ahora bien, opino que, en el punto en el que están mis conocimientos sobre el tema, cualquiera que juzgue con imparcialidad los resultados de este trabajo, asi como los que publicaré próximamente, reconocerá conmigo que la fermentación se muestra como algo correlativo a la vida y a la organización de glóbulos, y no a la muerte y a la putrefacción de esos glóbulos, y que tampoco aparece como un fenómeno de contacto, en el que la transformación del azúcar se llevaría a cabo en presencia del fermento sin darle nada ni tomar nada de el. Estos últimos hechos, como veremos en seguida, son contradichos por la experiencia.

Presentadme colegas imparciales y reconocerán conmigo lo que la experiencia afirma sin ningún género de duda; esa misma experiencia a la que, en la cita precedente, había que añadir no obstante algunos presupuestos porque no podía demostrar de manera irrefutable la presencia de microorganismos. ¡Contradicción flagrante! Los historiadores sociales que, por ascesis, se prohíben a sí mismos recurrir a una experiencia incontestable para acabar con las controversias, ya no aplauden al gran hombre.

Sin embargo, Pasteur pasa de una epistemología a otra sin pestañear, de la misma manera que el fermento, denominado $x$, pasa suavemente del acontecimiento a la substancia. Antes de Whitehead no podiamos salir de este dilema. Parecía que siempre debíamos elegir entre dos males, como una gota de agua a la que un golpe de viento hiciera pasar de un lado a otro de una vertiente. O bien la gota de agua acababa cayendo hacia el valle de la inventividad humana, cuya historia resulta fácil de hacer, porque ímpone categorías más o menos arbitrarias a una realidad que nunca nos será cognoscible, o bien la gota se deslizaba hacia el otro valle, el de la naturaleza, con objetos sin historia y presentes desde siempre, que los humanos se contentarían con descubrir.

Whitehead abre una nueva posibilidad y nos permite comprender por qué la contradicción sólo es aparente. El fermento del ácido láctico cambia su historia en contacto con Pasteur y con su laboratorio. Es perfectamente real, pero su realidad histórica le pone al mismo nivel que al investigador y al laboratorio con los cuales se mezcla. El ácido láctico también ha mutado. El fermento ha considerado el empujón que le dio Pasteur como una oportunidad histórica de manifestarse modificando toda su trayectoria. El fermento propone, Pasteur dispone. Pasteur propone, el fermento dispone. Pasteur no ha impuesto su manera de ver a una forma infinitamente plástica, ni ha descubierto a tientas la resistencia de una forma infinitamente robusta: ha dado su oporturidad a un fenómeno. Por eso, al escribir su Memoria, no ve ninguna contradicción entre las dos últimas citas, las cuales, sin embargo, se distinguen por completo a ojos de un epistemólogo o de un historiador social. Una ontología, todavía más contraintuitiva que la de la historia social de las ciencias, nos permite introducirnos en el sentido común de un sabio. Sería preciso que pudiéramos comprender esta frase enigmática, que pronunció a lo largo del elogio académico que Pasteur hizo de Littré al relevarle en el sillón: 
El experimentador, hombre dado a la conquista de la naturaleza, se encuentra confrontado sin cesar con hechos que todavia no se han manifestado y que no existen, en su mayor parte, más que en la potencia del devenir de las leyes naturales. Lo desconocido dentro de lo posible, y no dentro de lo que ha sido (contrariamente al historiador Littre), he ahi su dominio [...].20

\section{Whitehead a prueba}

¿Por qué esta solución al problema de la historícidad de las cosas, aunque la cmpujemos hacia el rincón del sentido común, a primera vista se nos aparece como algo tan inverosímil e insensato? A causa de nuestras ideas sobre la naturaleza, sobre la trascendencia y sobre la causalidad, ideas que Whitehead nos permite aligerar considerablemente.

Supongamos que calculamos los ingredientes que intervienen en la composición del ácido láctico de 1857, con el fin de comprender la coproducción de ese hecho científico. Una vez abandonados los relatos de descubrimiento a la antigua, así como los relatos de construcción social, mucho más recientes, debemos hacer una lista heterogénea que incluya, entre otros muchos factores, a Pasteur, a la Facultad de Ciencias de Lille, a Liebig, a las queserías, a los instrumentos de laboratorio, a la levadura de cerveza, al azúcar y, por último, al fermento. Ningún tipo de esencialismo se incluye en esta lista, puesto que cada entidad se define únicamente por sus relaciones. Si las relaciones cambian, la definición cambia de modo parejo; la Facultad de Ciencias no es exactamente la misma Facultad con o sin Pasteur; el azúcar con fermento láctico, o sin ćl, no es exactamente el mismo azúcar; antes y después de 1857, el fermento láctico ya no es el mismo fermento.

¿Basta esto para crear historia? No, y sabemos muy bien por qué. La historia no puede definirse como una pura reordenación de factores, porque, a diferencia de una receta de cocina, no se hace a partir de ingredientes. Por muy heterogéneas y relativas que sean las entidades que entran en una combinación así, la historicidad no surge a partir de eso. El fermento láctico no se compone de ingredientes dispersos por doquier, ni tampoco de asociaciones, como sucede en la teoría, no obstante radical, de los actores-red., ${ }^{21}$

Para evitar el atomismo de los factores y el chirrido de las combinaciones de dichos factores, hay que reconocer algo más a todo compuesto, a toda concreción: alguna capacidad radical y única de innovación. Para ello hay que aceptar que los acontecimientos, si de verdad han de merecer su nombre, en parte no tienen causa. Por absurdo que esto parezca, el realismo exige que se abandone la idea de la causalidad como una transferencia o un desplazamiento de fuerzas. El descubrimiento del fermento en 1857 no se debe a Pasteur, ni a los presupuestos que aportó, ni al laboratorio donde se definió lo que es una buena práctica, ni al fermento presente desde toda la eternidad y llevado a la Facultad de Lille, ni tampoco, por supuesto, al des- 
menuzamiento de pequeñas condiciones infinitesimales que, aun sin poder ser calculadas, actuarían cada una de ellas como una causa. Para que haya historia, hace falta que el fermento - de 1857 - de Pasteur - en Lille sea, en parte, causa sui. ${ }^{22}$ En ningún lugar del universo cabe encontrar una transferencia de fuerzas que permitan hacer la suma correspondiente a dicho acontecimiento, con el fin de explicar retrospectivamente su emergencia. El descubrimiento-invención-construcción del fermento láctico requiere que se le dé el estatuto de mediación, es decir de una ocurrencia que no es en verdad ni por completo una causa, ni por completo una consecuencia, ni por completo un medio, ni por completo un fin ${ }^{23}$. Se puede comprender a Pasteur como un acontecimiento del fermento porque es imprevisto y externo a la serie de herencias que definían hasta entonces la "sociedad" del microorganismo, su trayectoria, su estirpe. Por el hecho de reencontrarse en el laboratorio para ser sembrado, cultivado, relatado y purificado, el fermento se va a manifestar de una manera imprevisible. De manera correlativa, la presencia duradera de un fermento asociado a una fermentación, la actividad química de un ser vivo, constituye, para Pasteur, una bifurcación decisiva para su carrera y para su persona. En cuanto a los químicos, al aceptar a Pasteur y a su fermento, pasan a ser bioquímicos, por medio de una traducción decisiva. Como bien se puede comprender, ningún ingrediente interviene en esas relaciones sin refundirse.

Mientras se pensaba en la naturaleza como el reino de las causas, parecía inverosímil hablar de una historicidad de las cosas. La inventividad, la flexibilidad, la duda, sólo podían proceder de los seres humanos y de su dolorosa historia. Sólo ellos eran capaces de trascender el reino bruto de los objetos y afirmar su libertad contra las viscosas constricciones de lo práctico-inerte. Al vincular los humanos y los no humanos, el principio generalizado de simetría produjo escándalo, porque equivalía a extender la noción de persona a los seres naturales - panpsiquismo, hilozoísmo- $o$, por el contrario, a hundir la invención de los humanos en el juego más o menos previsible de las causas -mecanicismo, ingeniería social. ${ }^{24}$ iQué diferente sería si todas las entidades desbordasen, trascendiesen y superasen en parte sus causas, sus herencias, sus ascendencias! Los objetos de la naturaleza no ofrecerían ya, como único modelo ontológico, esa exigencia terca, obstinada y testaruda de la sustancia. Nada impide ya que se les conceda de nuevo un papel en la fábrica del mundo humano, sin volver al realismo a la antigua que los historiadores sociales combatieron con razón, y sin embargo sin caer en la acusación de atribuir a los no humanos esa personalidad intencional que estaba reservada hasta ahora sólo para los seres humanos. La naturaleza y la sociedad comparten el mismo tipo de historicidad, sin que por ello ese conjunto reunificado devenga inmanente o trascendente, impersonal o personal. La trascendencia que es necesaria para la innovación se distribuye entre todos los pequeños desenganches mediante los cuales las consecuen- 
cias desbordan su herencia. La historia de las ciencias pasa a ser, para bien, el existencialismo extendido a las cosas mismas. Al volver a hacerla histórica, la naturaleza pasa a ser todavía más interesante, más realista. ${ }^{25}$

En cuanto a la vertiente de la sociedad, se transforma todavía más, aproximándose al sentido común. Ya no se es prisionero por siempre del lenguaje, encerrado en los marcos conceptuales, privado a perpetuidad de todo acceso a las cosas mismas, a las cuales, como en el caso de Kant, no podriamos imponerles más que categorías arbitrarias. Nuestro espíritu, nuestra cultura, nuestros paradigmas dejan de ser moldes. Pese a sus dudas, Pasteur no dictó a los hechos cómo debían hablar. Se mezcló con ellos y compartió con ellos su historia, su cuerpo, su laboratorio y la asamblea de sus colegas, ofreciéndoles otra oportumidad. Los descubría tanto como los modelaba. Todos se coaligan en esta ocasión, materia y forma de los unos y de los otros.

Whitehead se burló amablemente de los filósofos criticos que creyeron que nuestro espíritu sólo está ligado al mundo por la frágil pasarela de la percepción, como si una gran ciudad, plenamente abierta hasta entonces al campo circundante, hubiera decidido encerrarse poco a poco detrás de sus murallas hasta el punto de no autorizar otra vía de paso más que a través de un estrecho portillo y de un puente levadizo bamboleante. Toda la filosofia del conocimiento surge de esta fragilidad, artificialmente mantenida, como si el espíritu corriera en todo momento el riesgo de perder sus preciosas provisiones. Demoled las murallas, autorizad otras vías de paso, abrid por completo la ciudad al campo, suprimid los fielatos: no faltarán los contactos entre el espíritu y el mundo. No hay riesgo de ruptura en las importaciones, puesto que ya no tenemos que privarnos, por ascetismo, de acudir a las cosas de la naturaleza, ampliamente accesibles, trascendentes como nosotros, históricas como nosotros, mestizas como nosotros.

Al compartir la trascendencia con los objetos y al acceder a ellos por los mil conductos del lenguaje, de la práctica y de la vida social, ya no estamos obligados a reducir las circunstancias, sea a la naturaleza, sea a la sociedad, sea al discurso. Basta con ponerlas «en red» - pero esta palabra, que ya habíamos utilizado, posee ahora la ontología adecuada a sus ambiciones, gracias a Whitehead. Cada ocurrencia llena exactamente, sin exceso ni defecto, su único envoltorio espacio-temporal. No existe ser alguno, como el fermento láctico o la gravitación universal, que «desborde» sus condiciones históricas de emergencia - lo cual no equivale a decir, sin embargo, que sólo sea el resultado del trabajo humano. Precisamente lo que ya no tenemos que hacer es elegir entre esas dos versiones. Para que cada ocurrencia se extienda y dé la impresión de «desbordar", le hacen falta otras condiciones históricas, otros apoyos, otros vehículos, otras mediaciones, todas ellas en parte causas de sí mismas.

Esta disposición en red de las ontologías sólo nos resulta difícil por el 
uso desconsiderado que hacemos de dos parejas de locuciones adverbiales, 'siempre/jamás' y 'por doquier / en ninguna parte'. A partir de la emergencia del ácido láctico, en 1857 y con Pasteur, concluimos que «siempre» ha estado ahí, y también que actúa "por doquier». Puesto que Pasteur deshizo en Lille, en 1857, la teoría de Liebig sobre la fermentación por degradación de las materias, concluimos que ésta "nunca" estuvo presente, "en ninguna parte". Exageración doble que congela la historia de las cosas y obliga a inventar a continuación, por contraste, esos relatos de descubrimiento por cuya crítica empecé este artículo. Puesto que el fermento había existido siempre, aunque hubiera sido ignorado hasta 1857, y puesto que los sabios son los únicos que se preocupan de estas cuestiones, es preciso que Pasteur lo haya descubierto levantando, por su virtud, el velo que lo encubría. Sin embargo, tanto Pasteur como sus colegas, los queseros, los mantequeros y los historiadores, deben trabajar mucho con el fin de extender al pasado la presencia retrospectiva del fermento de ácido láctico. En 1858, 1859, 1860, etc, deben proceder a una "evccación" de todos los siglos precedentes con el fin de darles este nuevo atributo: la presencia del fermento recién descubierto. Los historiadores trabajan como los editores de programas informáticos, que reemplazan por una suma módica la versión 2.1 de un programa por la nueva versión 2.2. Es preciso que trabajen tanto en el espacio como en el tiempo para extender a todas las lecherias y queserías la presencia, muy pronto universal, del fermento láctico. También hay que trabajar quitando de la historia pasada la teoría de Liebig y suprimiéndola poco a poco de todos los manuales -hasta el "descubrimiento" de los enzimas, más avanzado el siglo, que remodeló de nuevo a los fermentos, a Pasteur, a Liebig y a la historia retrospectiva de la bioquímica. A lo largo de su historia, el fermento láctico nunca exagera su existencia ni su falta de ser, como tampoco su localización ni su universalidad. Al igual que las otras entidades, persevera en el ser, pero sólo un poco, en ciertos lugares, durante un cierto tiempo, con la condición de existir en común con otros muchos que, ellos tampoco, no acceden ni a la substancia ni a la nada, sino que «deciden" en las bifurcaciones sobre su historia. Filamentos, linajes, trayectorias, herencias, sociedades, rizomas.

Espero haber mostrado, como me había propuesto hacer, que la metafísica de Whitehead permite dar un paso decisivo en la filosofía de la historia de las ciencias, que estaba bloqueada desde algún tiempo en torno al problema del papel que conviene atribuir a los no humanos. También desde un punto de vista empírico Whitehead ofrece buenos resultados, puesto que permite explicar que una contradicción en el informe experimental de Pasteur no es tal contradicción, a partir del momento en que decidimos abandonar el reino único de las causas. Gracias a él, los circuitos en los que se divide esta historia, los fermentos, los sabios, los laboratorios y los colegas, pasan a ser todavía más accesibles para la indagación historica, sin perder por ello su realismo. A través de un largo rodeo por el 
kantismo, por el relativismo radical y por el principio restringido, y luego generalizado, de simetría, volvemos gracias a la ontología al sentido común que Whitehead nos aconsejó, con cierto humor, respetar siempre. ${ }^{26}$

\section{NOTAS}

1. A.N. Whitehead, Process and Reality. An Essay in Cosmology, Nueva York, Free Press, 1929 (1978), p. 79.

2. La presentación canónica de este principio se encuentra en $H$. Collins, Changing Order. Replication and Induction in Scientific Practice, Londres / Los Ángeles, Sage, 1985.

3. Los ejemplos más elaborados están expuestos en S. Shapin y S. Schaffer, Le Léviathan et la pompe à air - Hobbes et Boyle entre sciertce et politique, Paris, La Décotverte, 1993, y en C. Licoppe, Eprouver, rapporter et convaincre. Une étude du compte-rendu expérimental à l'époque moderne, tesis de doctorado, Paris VI, 1994.

4. I. Stengers, L'invention des sciences modernes, París, La Décotwerte, 1993.

5. A.N. Whitehead, o.c., p. 43.

6. La presentación canónica la hizo D. Bloor en Sociologie de la logique ou les limites de lépistémologie, París, Pandore, 1982. Para una justificación reciente vénse el prefacio a la segunda edición de D. Bloor, Knowledge and Social Imaginery (2." ed. con un nuevo prólogo), University of Chicago Press (1976), 1991.

7. Su forma mâs extrema está expuesta en G. Canguilhem, Études d'histoire et de philosophie des sciences, Paris, Vrin, 1968.

8. Esta frase de toque de atención aparece incluso en el último párrafo de un libro por lo demás sofisticado, como el de S. Shapin y S. Schaffer, o.c.

9. Véanse sus expresiones canónicas en B. Latour, Les microbes, Guerre et Paix suivi d'Irréductions, París, A.-L. Métailié, col. Pandore, 1984, segunda parte, así como en M. Callon, "Eléments pour une sociologie de la traduction. La domestication des coquilles Saint-Jacques et des marins pêcheurs en baie de Saint-Brieucs, Lannée sociologique, vol. 36 (1986), pp. 169-208, y en B. Latour, La science en action. París, La Découverte, 1989.

10. Véase B. Latour, Nous viavons jamais été modemes. Essai d'anthropologie symétrique, París, La Découverte, 1991, para una presentación de la filosofia de esta teoria de los actores-red.

11. Se encontrará un análisis semiótico del articulo en B. Latour, "Pasteur on lactic acid yeast - a partial semiotic analysis", Configurations, vol. 1 (1) (1993), pp. 127-142. Para una presentación general del pasteurismo, la mejor fuente sigute siendo G. Geison, aArticle Pasteurw, en la obra dirigida por G. Gillispie, The Dictionnary of Scientific Biography, Nueva York, Scribner and Sons, 1974, pp. 351-415. Utilizo aquí únicamente el texto de Pasteur, con el fin de extraer de él sus ontologías variables, sin preoctuparme de otros archivos o huellas que seguramente me pondrían más en relación con el laboratorio y la práctica de Pasteur.

12. Para una presentación de los químicos y de sus ideologias profesionales, véase $B$. Bensaude-Vincent e I. Stengers, Histoire de la chinie, París, La Découverte, 1992.

13. Sorprenderán las similitudes entre A.N. Whitehead, o.c., y este admirable libro sobre la filosofia china: F. Julien, La propension des choses, Patís, Le Seull, col. Travaux, 1992.

14. Véase el artículo seminal de F. Jacq, «La philosophie de lexplication historique en histoire et en listoire des sciences», CSI (pendiente de aceptación), 1993.

15. En S. Schaffer, "The Eighteenth Brumaire of Bruno Latour", Studies in History and Philosophy of Science, val, 22 (1991), pp. 174-192, y en H. Collins y S. Yearley, "Epistemological Chickens, en A. Pickering (ed), Science as Practice and Culture, Chicago, Chicago University Press, 1992, pp. 301-326, se encontraran dos criticas muy severas al principio generalizado de simetráa. Para una respuesta, escrita en la lógica de los actores-red, que el presente artículo quiere enmendar, vease $M$. Callon y B. Latour, $*$ Don't throw the Baby out with the Bath School!s, en A. Pickering, o.c., pp. 343-368. 
16. De hecho, se trata de proporcionar una ontología a esta frase de Kuhn, que en su caso tiene un sentido psicosocial: «Aunque el mundo no cambie después de un cambio de paradigma - escribe- el hombre de ciencia trabaja después en un mundo diferente. Estoy convencido de que debemos aprender a encontrarle un sentido a esta afirmacion [...] No es posible reducir lo que sucede en una revolución científica a una reinterpretación de datos estables e independientess (T. Kuhrn, La structure des révolutions scientifiques. París, Flammarion, 1983, p. 171).

17. Tomo estos terminos del excelente articulo de J.B. Cobb, "Alfred North Whitehead", en D.R. Griffin (ed.), Founders of Constructive Postmodem Philosophy, Albany, State University of Nueva York Press, 1993.

18. El error de Schaffer en Schaffer, o,c, consiste en conceder la interpretative flexibility únicamente a los investigadores confrontados con los datos. Según él, introducir a los no humanos equivaldria siempre a reducir las controversias al silencio. En cambio, Hacking no tiene dificultad alguna en proponer una interpretación constructivista de los hechos sociales, puesto que se da por entendido, de una vez por todas, que sólo pueden corresponder a lo arbitrario de las profecías autorrealizadoras (I. Hacking, "World-Making by Kind-Making: Child Abuse for Example», en M. Gouglas y D. Hull [eds.], How Classification Works, Edimburgo, Edinburgh University Press, 1992, pp. 180-237).

19. Pata prosegutír con esta historia natural de los seres involucrados en los circuitos cientificos, véașe B. Latour, La science en action, o.c.

20. L. Pasteur, Oeurres Complètes, 7 vols., Paris, Masson, 1939, tomo VII, p. 334.

21. La teoría de los actores-red trata más bien de conjuntar dos modelos, uno explícito sobre la asociación, el otro subrepticio sobre la acción. Para hacer intervenir a esta última, le falta una ontología que se adapte al principio generalizado de simetría.

22. "Todas las entidades actuales comparten con Dios esta caracteristica de la autocausación. Por esa razón, toda entidad actual comparte también con Dios la caracteristica de trascender al resto de entidades actuales, incluido Diosn (A.N. Whitehead, o.c., p. 223).

23. Sobre la noción de mediación en el dominio privilegiado del arte musical, véase el excelente libro de A. Hennion, La passion musicale. Une sociologie de la médiation, París, A.-M. Métailié, 1993.

24. El paso de una visión previsible de las causas a una concepción del orden por el desorden, curiosamente, no ha modificado esta alternativa, a pesar de I Prigogine e I. Stengers, Entre le temps et l'étemité, Paris, Fayard, 1988. La noción de emergencia, pese a ser tan de Whitehead, no implica forzosamente la historización simétrica de la natumleza y de la sociedad.

25. Esta historicidad no debe ser confundida con la transformación en el tiempo de las partículas o de los seres vivos, como en los grandes relatos cosmologicos o evolucionistas (S.J. Gould, La vie est belle, París, Le Seuil, 1991). Al invertir el principio antrópico, se trata de introducir a los sabios en la historia de las cosas. No sólo de contar cómo desaparecieron los dinosatrios, sino cómo participan los paleontologos en la historia misma de los dinosaurios - dos formas de historicidad complementarias pero distintas.

26. En la redacción de este artículo me he beneficiado de las críticas de Christiane Frémont, tan pertinentes que no he podido extraer de ellas todo lo que hubiera querido.

\section{BIBLIOGRAFIA DE LATOUR TRADUCIDA AL CASTELLANO}

La vida del laboratorio. La construcción social de los hechos cientificos, Madrid, Alianza, 1995. Nunca hemos sido modemos. Ensayo de antropologfa simétrica, Madrid, Debate, 1993. Ciencia en acción, Barcelona, Labor, 1992.

«Pasteur y Pouchet: heterogénesis de la historia de la ciencia», en M. Serres (ed.), Historia de la Ciencia, Madrid, Cátedra, 1985, pp. 477-501.

«Joliot: punto de encuentro de la historia y de la físican, en M. Serres, op. cit., pp. 553-573. "Etnografia de un caso de alta tecnología: sobre Aramis», Politica y Sociedad, 14-15, pp. 77-97. 